\title{
Therapeutic efficacy of intra-tumor AvidinOX and low systemic dose biotinylated cetuximab, with and without cisplatin, in an orthotopic model of head and neck cancer
}

\author{
LOREDANA VESCI ${ }^{1}$, VALERIA CAROLLO $^{2}$, ANTONIO ROSI $^{1}$ and RITA DE SANTIS ${ }^{1}$ \\ ${ }^{1}$ Biotechnology R\&D, Alfasigma S.p.A., Pomezia, I-00071 Rome; ${ }^{2}$ Histo-Cyto Service, I-00151 Rome, Italy
}

Received July 19, 2018; Accepted January 17, 2019

DOI: $10.3892 / \mathrm{ol} .2019 .10003$

\begin{abstract}
In a previous study, the efficacy of low intraperitoneal doses of biotinylated cetuximab (bCet) in mice with subcutaneous tumor xenografts of human head and neck cancer (HNC) treated intra-tumors with AvidinOX was reported. Taking into account that the current standard treatment for HNC is the combination of cetuximab and cisplatin, the present study investigated the activity of AvidinOX-targeted bCet with and without cisplatin in an orthotopic model. The results confirmed that administration of intra-tumor AvidinOX makes an otherwise inactive dose of bCet effective in reducing tumor growth, and the addition of a low dose of cisplatin further improved tumor growth inhibition. Supporting the in vivo data, immunohistochemical staining of tumor masses from mice treated with AvidinOX, bCet and cisplatin exhibited the highest tumor cell damage and the lowest angiogenic activity among all treatment groups, measured as the number of $\gamma-\mathrm{H} 2 \mathrm{~A} . \mathrm{X}$ and cleaved caspase-3-positive cells, and vascular endothelial growth factor- $\mathrm{C}$ and platelet and endothelial cell adhesion molecule 1-positive cells, respectively. AvidinOX is currently under clinical investigation to assess its use in delivering radioactive biotin to inoperable tumor lesions (ClinicalTrials. gov: NCT02053324 and NCT03188328). The present study further supported the potential clinical use of AvidinOX to target low bCet doses to inoperable tumor lesions, with or without an additional low dose of cisplatin. Since low doses of highly expensive monoclonal antibodies become effective with AvidinOX and low dose cisplatin, such therapies promise to be cheaper and less toxic than current treatments.
\end{abstract}

\section{Introduction}

Head and neck cancer (HNC) is the sixth most common cancer worldwide. At present, 650,000 new cases of HNC

Correspondence to: Dr Rita De Santis, Biotechnology R\&D, Alfasigma S.p.A., Via Pontina km 30.400, Pomezia, I-00071 Rome, Italy

E-mail: rita.desantis@alfasigma.com

Key words: AvidinOX, biotinylated cetuximab, cisplatin, cancer are diagnosed globally each year (1). Cisplatin is the most widely used cytotoxic drug and, as the epidermal growth factor receptor (EGFR) is almost invariably expressed in $\mathrm{HNC}$, drugs targeting EGFR have also been employed as HNC therapeutics. Anti-EGFR monoclonal antibodies, cetuximab and panitumumab, have produced some improvement in survival when used in combination with cytotoxic drugs to treat recurrent or metastatic disease $(2,3)$. However, recent large clinical trials of anti-EGFR monoclonal antibodies or tyrosine kinase inhibitors used in addition to platinum-based chemoradiation regimens have produced disappointing results $(4,5)$. Moreover, adding cetuximab to chemoradiotherapy may enhance toxicity and, thus, requires further investigation (6). Therefore, it is important to improve the therapeutic efficacy of current HNC interventions. We recently described a novel method that allows suboptimal doses of biotinylated agents to become effective therapies in models of HNC. The treatment is based on the intra-tumor injection of AvidinOX, an oxidized avidin derivative that exhibits the distinctive property of forming Schiff's bases with tissue proteins (7-11), followed by systemically administered radioactive biotin (12) or biotinylated cetuximab (bCet) (13). In the present study, we show that the injection of AvidinOX into FaDu pharynx squamous cell carcinoma cells xenografted in the mouse tongue increases the anti-tumor activity of a suboptimal bCet dose administered intraperitoneally after $24 \mathrm{~h}$. The data also indicate that the treatment can be repeated at least twice, 1 week apart, and that the therapeutic efficacy could be further improved by including a low dose of cisplatin in the protocol. AvidinOX is currently under clinical investigation for use in targeting ${ }^{177}$ lutetium-biotinDOTA $\left({ }^{177} \mathrm{Lu}-\mathrm{ST} 2210\right)(14)$ to inoperable tumor lesions (ClinicalTrials.gov NCT02053324 and NCT03188328). The present results support that using an intra-tumor injection of AvidinOX prior systemic administration of low dose bCet (with or without cisplatin) may be useful in patients with $\mathrm{HNC}$.

\section{Materials and methods}

Cells and reagents. Human $\mathrm{FaDu}$ squamous cell carcinoma of the pharynx cells were obtained from the American Type Culture Collection (Manassas, VA, USA; ATCC ${ }^{\circledR} \mathrm{HTB}^{-43^{\mathrm{TM}}}$ ) and maintained in a humidified atmosphere with $5 \% \mathrm{CO}_{2}$ at $37^{\circ} \mathrm{C}$. Working cell banks were established and all experiments were performed using cells within 6-8 passages after thawing. 
AvidinOX $^{\circledR}$ (registered brand of Alfasigma S.p.A., Rome, Italy) was prepared according to previously described methods (13) and the protein solution $(3.0 \mathrm{mg} / \mathrm{ml}$ in acetate buffer, $\mathrm{pH}$ 5.5) was stored at $-80^{\circ} \mathrm{C}$ until use. Cetuximab (Erbitux ${ }^{\oplus}$; Merck KGaA, Darmstadt, Germany) was biotinylated and controlled as previously described (12). Cisplatin (cis-diamine-platinum-dichloride; cat. no. P4394; Sigma-Aldrich; Merck KGaA) was dissolved in saline solution before administration.

Animal model. Female athymic nude mice, 5-6 weeks old, were purchased from Charles River Laboratories (Wilmington, MA, USA). The present study was approved by the Ethics Committee of Alfasigma S.p.A., (Pomezia, Rome, Italy) and authorized by the Italian Ministry of Health (46/2014-PR). Animal studies were performed in accordance with the 'Directive 2010/63/UE' on the protection of animals used for scientific purposes, made effective in Italy by the Legislative Decree 4 March 2014, n. 26, and ARRIVE guidelines (15). At the end of the treatment period, mice were euthanized by $\mathrm{CO}_{2}$ asphyxia (air displacement rate, 20\%/min) as indicated in the American Veterinary Medical Association Panel on Euthanasia and according to the guidelines described by the United Kingdom Co-ordinating Committee on Cancer Research (1998). Mice were maintained in a pathogen-free facility and the tongue was inoculated with $50 \mu 1$ suspension of FaDu cells $\left(4 \times 10^{5}\right)$ in Hanks' balanced salt solution with Matrigel RGF (1:1). Tumor-bearing mice were randomized into groups of 10 and received $75 \mu \mathrm{g} / 25 \mu 1$ AvidinOX intratumorally or the same volume of AvidinOX formulation buffer (vehicle) $24 \mathrm{~h}$ before each drug administration. At 5 days before the first drug treatment, mice were switched to a biotin-free diet. Treatments were first administered at 19 days after tumor transplantation. bCet and cisplatin were delivered intraperitoneally at the indicated doses according to the schedule Q7dx2. The doses of bCet and cisplatin were selected, based on preliminary studies, to induce tumor growth inhibition of $20 \%$. Tumor measurements were performed using a digital Vernier caliper twice per week and tumor volume (TV) calculated using the following equation: Volume=length $\mathrm{x}(\text { width })^{2} / 2$. Efficacy of treatment was assessed as TV inhibition percentage (TVI\%) in treated vs. control mice, calculated as: TVI $\%=100$ - $($ mean TV treated/mean TV control x 100). Body weight was recorded throughout the study. Tumor doubling time was extrapolated from semi log best-fit curves of mean tumor volumes plotted against time. Doubling time was the $\ln 2 / \mathrm{b}$ where $\mathrm{b}$ was the slope of linear regressions. Mice were euthanized 5 days after the second treatment. At $24 \mathrm{~h}$ before sacrifice, mice received a further intraperitoneal injection of bCet, cisplatin or both.

Histology and immunohistochemistry (IHC). Tumor masses were harvested and fixed in $10 \%$ phosphate-buffered formalin for $12 \mathrm{~h}$ at $4^{\circ} \mathrm{C}$. Samples were then dehydrated in ascending concentrations of ethanol, cleared with xylene and paraffin embedded. Tissue slices were obtained using a rotary microtome (5 $\mu \mathrm{m}$ sections) and processed for IHC. For histology, hematoxylin/eosin staining was performed according to standard methods.

Briefly, after deparaffination and rehydration, sections were treated with $0.01 \mathrm{~mol} / \mathrm{l}$ citrate buffer and $0.05 \%$ Tween 20
(pH 6.0; Sigma-Aldrich; Merck KGaA, Darmstadt, Germany) in a microwave for $15 \mathrm{~min}$ for antigen retrieval, followed by quenching of endogenous peroxidase activity with $3 \% \mathrm{H}_{2} \mathrm{O}_{2}$ in PBS (v/v) for $5 \mathrm{~min}$. Sections were then incubated with specific antibodies against phospho- $\gamma-\mathrm{H} 2 \mathrm{~A}$ histone family member $\mathrm{X}$ (H2A.X; Ser139; cat. no. 20E3) and cleaved caspase-3 (cat. no. 9664), from Cell Signaling Technology, Inc., (Danvers, MA, USA), or against platelet and endothelial cell adhesion molecule 1 (CD31; cat. no. ab28364) or vascular endothelial growth factor-C (VEGF-C; cat. no. ab135506) from Abcam (Cambridge, UK), diluted in blocking buffer (5\% goat serum in $0.05 \%$ Triton X-100 and PBS for $\gamma$-H2A.X and cleaved caspase-3; $10 \%$ goat serum in PBS for CD31; and 5\% goat serum in $0.05 \%$ Triton X-100 and TBS for VEGF-C) overnight at $4^{\circ} \mathrm{C}$ in a humidified chamber. Negative controls were incubated without primary antibodies under identical conditions. Sections were then incubated with the appropriate biotinylated secondary antibody (1:300), followed by conjugated horseradish peroxidase-streptavidin (ABC kit; Vector Laboratories, Inc., Burlingame, CA, USA) and 3,3'-diaminobenzidine (ABC kit) working solution, then counterstained with hematoxylin. Images were captured using an optical microscope (Eclipse E800; Nikon Corporation, Tokyo, Japan) with a JVC KY-F55B color video digital camera.

IHC staining for $\gamma$-H2A.X and cleaved caspase-3 was quantified as the number of positive cells (brown cells) x 100/total number of cells, in five fields from two serial sections/mouse. The mean number of CD31-positive vessels per $\mathrm{mm}^{2}$ viable tumor for each xenograft was also quantified in 24 randomly selected fields for each tumor section. The results for VEGF-C were expressed according to semi-quantitative criteria: negative staining, score $0 ; 1-20 \%$ positive cells, score $1+; 21-50 \%$ positive cells, score $2+$; and $>50 \%$ positive cells, score $3+$. The staining intensity was scored on a scale as weak, moderate or strong (16).

All analysis of tissue sections was performed by two independent pathologists and data was subsequently confirmed by computerized measurements (17). Data are present as the mean \pm standard error (SE) of 10 mice/group.

Statistical analysis. All data are presented as the mean \pm standard error or standard deviation, and statistical analyses were performed using two-way analysis of variance followed by Bonferroni's multiple-group comparisons (GraphPad Prism v.7.05 Software; GraphPad Software, Inc., La Jolla, CA, USA). $\mathrm{P}<0.05$ was considered to indicate a statistically significant difference.

The effect of the combination of drugs was evaluated for the following groups: AvidinOX+cisplatin+bCet vs. cisplatin+bCet; AvidinOX+bCet vs. bCet; and cisplatin+bCet vs. single drugs; according to the method reported by Romanelli et al (18). R was calculated as the ratio of expected and observed $\mathrm{T} / \mathrm{C} \%$ values. An R index of 1 indicates an additive effect, $\mathrm{R}>1$ indicates synergism.

\section{Results}

Tumor growth inhibition. Mice with human FaDu tongue xenografts were treated with AvidinOX intra-tumorally, followed by intraperitoneal injection of bCet, with or without 

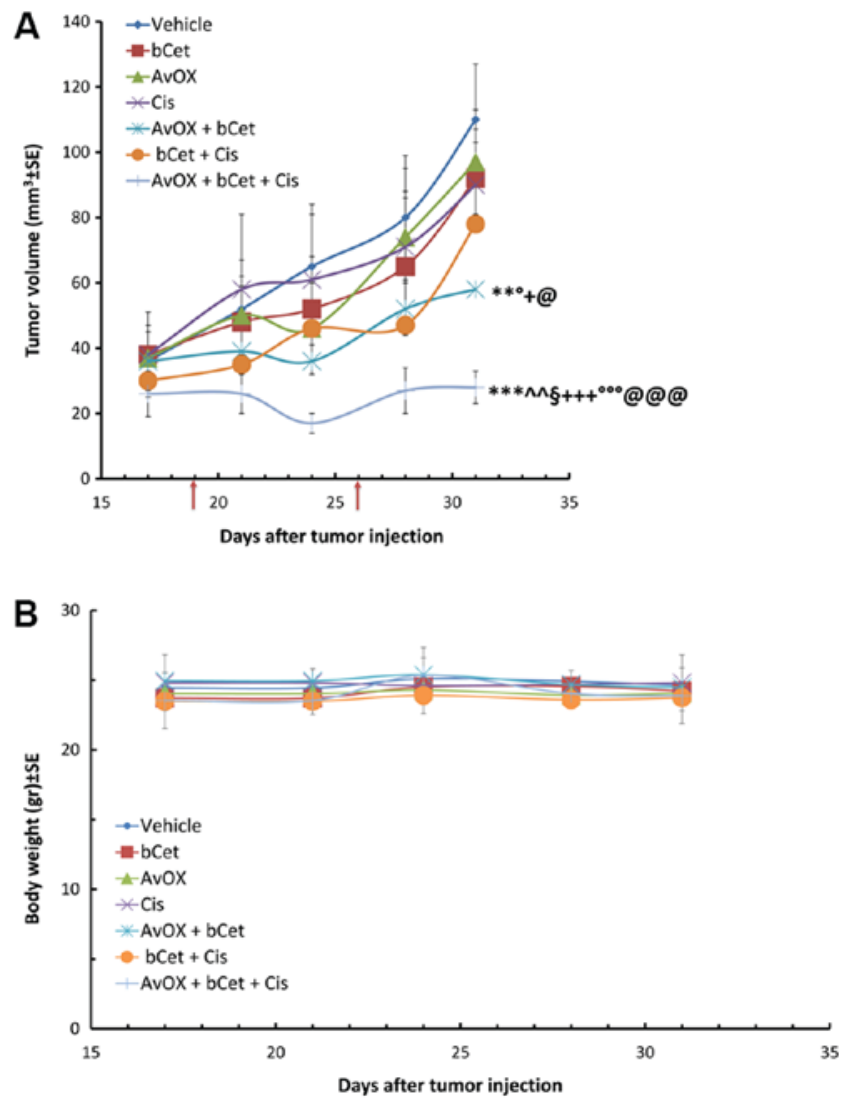

Figure 1. Low dose cisplatin increases AvOX-dependent tumor growth inhibition by bCet. (A) Human FaDu tumor cells $\left(4 \times 10^{5}\right)$ were xenografted in the tongue of mice. Treatment started at 19 days post-transplantation. AvOX (75 $\mu \mathrm{g})$ was administered intratumorally $24 \mathrm{~h}$ prior to intraperitoneal drugs: bCet $(40 \mu \mathrm{g})$, bCet and/or Cis $(5 \mu \mathrm{g})$ according to the schedule Q7dx2 (days 19,26). Tumor volume was measured using a Vernier digital caliper. (B) Body weight. Results were compared using two-way analysis of variance followed by Bonferroni's multiple comparison test. ${ }^{* *} \mathrm{P}<0.01$ and ${ }^{* * * *} \mathrm{P}<0.001$ vs. vehicle-treated group; ${ }^{+} \mathrm{P}<0.05$ and ${ }^{+++} \mathrm{P}<0.001$ vs. $\mathrm{AvOX} ;{ }^{\circ} \mathrm{P}<0.05$ and ${ }^{00} \mathrm{P}<0.001$ vs. bCet; ${ }^{\circledR} \mathrm{P}<0.05$ and ${ }^{@ @ @ ~}{ }^{\circ} \mathrm{P}<0.001$ vs $\mathrm{Cis} ;{ }^{\wedge \wedge} \mathrm{P}<0.01$ vs. bCet+Cis; ${ }^{\S} \mathrm{P}<0.05$ vs. AvOX+bCet. bCet, biotinylated cetuximab; AvOX, AvidinOX; Cis, cisplatin; SE, standard error; gr, grams.

a low dose of cisplatin. Data in Fig. 1A confirm results obtained in a previous study using $\mathrm{FaDu}$ subcutaneous tumor xenografts, which demonstrated the anti-tumor efficacy of low dose bCet in AvidinOX-treated tumors. These results are supported by in vitro data indicating that AvidinOX-anchored bCet causes induction of EGFR degradation, inhibition of EGFR nuclear translocation and downstream signaling, plus upregulation of pro-apoptotic and cell damage markers (13). In the current study, the tumor growth inhibition of bCet was further improved by additional administration of low dose cisplatin; in fact, tumor masses treated with AvidinOX in mice receiving low doses of intraperitoneal bCet and cisplatin were significantly smaller than the tumor masses of mice treated with AvidinOX+bCet, or bCet+cisplatin. No toxicity was observed among all experimental groups, as indicated by body weight measurement (Fig. 1B).

As shown in Table I, tumor volume inhibition at the end of the study (day 31) was significantly higher in mice treated with AvidinOX and low dose bCet, when a low dose of cisplatin was also administered compared to the other groups. The observed effect was higher than expected, based on the results of the AvidinOX $+\mathrm{bCet}$ or bCet+cisplatin treatment groups. The expected/observed ratio values of 1.4 and 2.5 indicate synergistic effects of AvidinOX+bCet and AvidinOX+bCet+cisplatin, respectively. Tumor doubling time in AvidinOX+bCet+cisplatin treated mice was also the lowest among the experimental groups confirming that the addition of low dose cisplatin to AvidinOX-targeted bCet can further delay tumor growth.

Immunohistochemistry analysis. Consistent with tumor growth inhibition, immunohistochemistry confirmed that tumor masses of mice treated with AvidinOX, bCet and cisplatin exhibited the highest level of tumor cell damage, as measured by the number of cells expressing phosphorylated $\gamma$-H2A.X (Fig. 2A) and cleaved caspase-3 (Fig. 3A). In fact, the treatment with AvidinOX $+\mathrm{bCet}+$ cisplatin induced a statistically significant increase in the number of $\gamma-\mathrm{H} 2 \mathrm{~A} . \mathrm{X}$ and cleaved caspase-3-expressing cells as compared to the bCet+cisplatin or AvidinOX+bCet treatment groups (Figs. 2B and 3B). Additional serial sections from the tumor masses of each experimental group were used to investigate angiogenesis. Microvessel density and lymphangiogenic activity were evaluated by counting the number of $\mathrm{CD} 31^{+}$cells and VEGF-C protein expression, respectively. The results showed that the anti-angiogenic activity of bCet was significantly enhanced by AvidinOX, whereas AvidinOX did not significantly improve the effect of bCet+cisplatin (Figs. 4 and 5). The combination of bCet+cisplatin without AvidinOX was better than bCet alone, but not better than cisplatin.

\section{Discussion}

There is a need to develop local treatments for cancer lesions that are derived from or reside within tissues/organs that are very different in terms of stromal composition, vascularization, density and other features. AvidinOX has been previously shown to form Schiff's bases with proteins in a variety of tissues and in several animal species (7-13). Long tissue residence of AvidinOX is also currently being confirmed in human patients with liver metastases and other inoperable tumor lesions as indicated by selective and consistent uptake of intravenous ${ }^{177} \mathrm{Lu}-\mathrm{ST} 2210$ administered 1 and up to 15 days after intra-tumor AvidinOX (ClinicalTrials.gov NCT02053324 and NCT03188328, data not shown). AvidinOX is a novel delivery tool for targeting a variety of biotinylated moieties. In fact, we recently published results that support the potential use of nebulized AvidinOX as an anchoring agent for nebulized biotinylated monoclonal antibodies (including cetuximab) for the topical treatment of lung cancer. Surprisingly, the in vitro potency of bCet, panitumumab, trastuzumab and pertuzumab is improved by the presence of AvidinOX on the surface of tumor cells $(19,20)$, suggesting that AvidinOX could be used as a delivery platform for a variety of potential therapeutic applications. Intra-tumor administration of AvidinOX shares similarities with other procedures common in clinical practice for diagnostic (i.e. biopsies) and therapeutic (seed/catheter deposition, alcoholization) purposes. Such procedures have not been linked with an increased risk of metastasis and we consider that AvidinOX injection would be similar.

The present work confirms and extends data from a previous study that showed the efficacy of using AvidinOX 
Table I. Tumor growth inhibition of AvOX-targeted bCet with and without cisplatin.

\begin{tabular}{|c|c|c|c|c|c|c|c|}
\hline Groups & $\begin{array}{c}\text { Dose }(\mu \mathrm{g} / \text { mouse }) \\
\text { Q7dx2: } 19,26\end{array}$ & $\begin{array}{c}\mathrm{TV} \pm \mathrm{SE} \\
\text { day }+31\left(\mathrm{~mm}^{3}\right)\end{array}$ & $\begin{array}{c}\text { TVI\% } \\
\text { day }+31\end{array}$ & $\begin{array}{l}\text { Observed } \\
\text { T/C\% }\end{array}$ & $\begin{array}{l}\text { Expected } \\
\mathrm{T} / \mathrm{C} \%\end{array}$ & $\begin{array}{c}\text { Expected/ } \\
\text { observed ratio }\end{array}$ & $\begin{array}{c}\text { TV doubling } \\
\text { time } \\
\text { (days } \pm \mathrm{SD})\end{array}$ \\
\hline Vehicle & 0 & $110 \pm 17$ & - & & & & $9.0 \pm 0.5$ \\
\hline bCet & 40 & $92 \pm 15$ & 16 & 84 & & & $11.8 \pm 1.5$ \\
\hline $\mathrm{AvOX}$ & 75 & $97 \pm 16$ & 12 & 88 & & & $10.4 \pm 1.9$ \\
\hline Cis & 5 & $90 \pm 13$ & 18 & 82 & & & $12.8 \pm 1.9$ \\
\hline $\mathrm{AvOX}+\mathrm{bCet}$ & $75+40$ & $58 \pm 8^{\mathrm{a}, \mathrm{c}, \mathrm{e}, \mathrm{g}}$ & 47 & 53 & 74 & $1.4^{\mathrm{k}}$ & $19.3 \pm 3.0$ \\
\hline $\mathrm{bCet}+\mathrm{Cis}$ & $40+5$ & $78 \pm 12$ & 29 & 71 & 69 & 1.0 & $10.7 \pm 1.6$ \\
\hline $\mathrm{AvOX}+\mathrm{bCet}+\mathrm{Cis}$ & $75+40+5$ & $28 \pm 5^{\mathrm{b}, \mathrm{d}, \mathrm{f}, \mathrm{h}, \mathrm{i}, \mathrm{j}}$ & 75 & 25 & 63 & $2.5^{\mathrm{k}}$ & $43.9 \pm 6.0$ \\
\hline
\end{tabular}

Data are presented as the mean $\pm \mathrm{SE}$ (n=10 mice per group) and were compared using two-way analysis of variance followed by Bonferroni's multiple comparison test. ${ }^{\mathrm{a}} \mathrm{P}<0.01$ and ${ }^{\mathrm{b}} \mathrm{P}<0.001$ vs. vehicle-treated groups; ${ }^{\mathrm{c}} \mathrm{P}<0.05$ and ${ }^{\mathrm{d}} \mathrm{P}<0.001$ vs. AvOX; ${ }^{\mathrm{e}} \mathrm{P}<0.05$ and ${ }^{\mathrm{f}} \mathrm{P}<0.001$ vs. bCet; ${ }^{\mathrm{g}} \mathrm{P}<0.05$ and ${ }^{\mathrm{h}} \mathrm{P}<0.001$ vs. Cis; ${ }^{\mathrm{P}}<0.01 \mathrm{vs}$. bCet+Cis; ${ }^{\mathrm{j}} \mathrm{P}<0.05$ vs. AvOX+bCet; ${ }^{\mathrm{k}} \mathrm{R}>1.0=$ synergism. Q7dx 2 , treatment administered once a week for 2 weeks on days 19 and 26 following the tumor injection; AvOX, AvidinOX; bCet, biotinylated cetuximab; Cis, cisplatin; SD, standard deviation; SE, standard error; TV, tumor volume; TVI, TV inhibition; Observed T/C\%, TV treated mice/TV control (vehicle-treated) mice $\mathrm{x}$ 100; Expected T/C\% AvOX+bCet, (Observed T/C\% AvOX x Observed T/C\% bCet)/100. Expected T/C \% bCet+Cis, (Observed T/C\% bCet x Observed T/C\% Cis)/100; Expected T/C\% AvOX+bCet+Cis, (Observed T/C\% AvOX x Observed T/C\% bCet+Cis)/100; Synergistic effect evaluated as described by Romanelli et al (18).

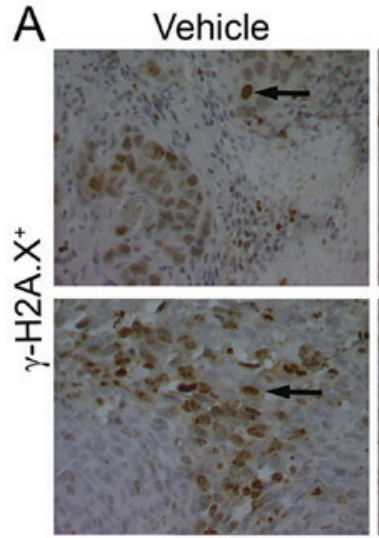

Cis

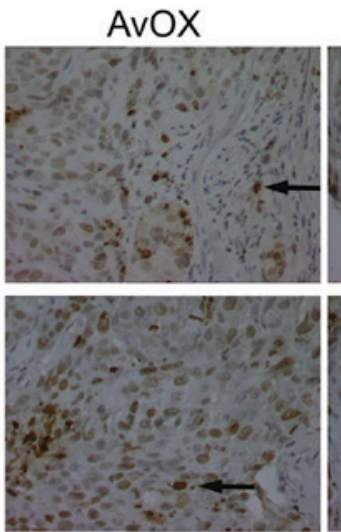

bCet+Cis

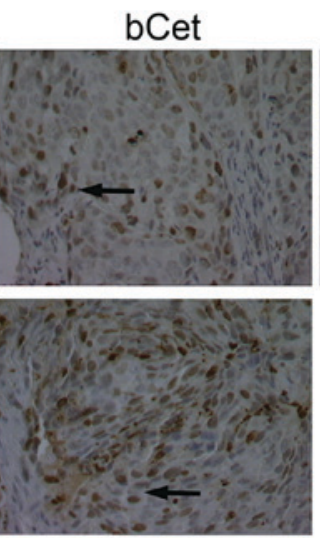

$\mathrm{AvOX}+\mathrm{bCet}+\mathrm{Cis}$

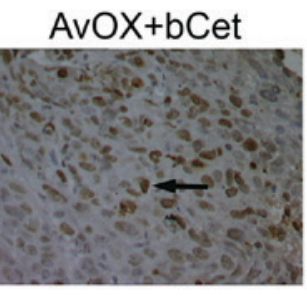

B

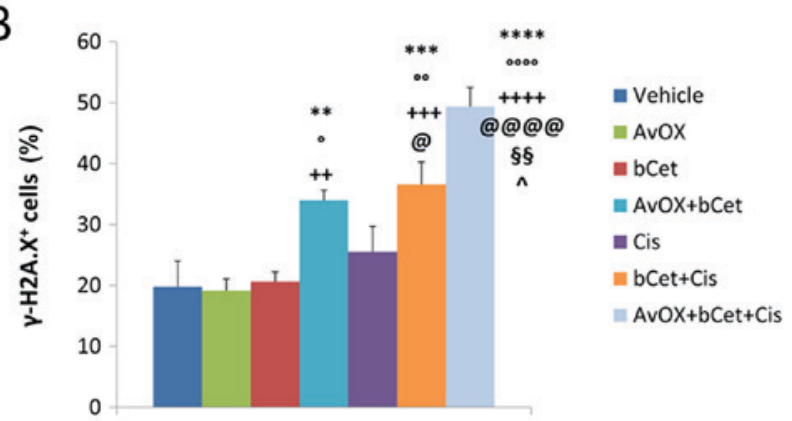

Figure 2. Low dose Cis increases the AvOX-dependent induction of $\gamma$-H2A.X positive tumor cells by bCet. (A) Representative images of $\gamma$-H2A.X staining (brown cells indicated by arrows). Magnification, $\mathrm{x} 40$. (B) Data are presented as the mean \pm standard error ( $\mathrm{n}=10$ mice per group) of positive cells $\mathrm{x}$ $100 /$ total cells counted by two independent observers in five randomly selected fields. Results were compared using two-way analysis of variance followed by Bonferroni's multiple comparison test. ${ }^{* *} \mathrm{P}<0.01,{ }^{* * *} \mathrm{P}<0.001$ and ${ }^{* * * *} \mathrm{P}<0.0001$ vs. vehicle-treated group; ${ }^{\circ} \mathrm{P}<0.05,{ }^{\circ} \mathrm{P}<0.01$ and ${ }^{\circ 000} \mathrm{P}<0.0001$ vs. bCet; ${ }^{++} \mathrm{P}<0.01$, ${ }^{+++} \mathrm{P}<0.001$ and ${ }^{++++} \mathrm{P}<0.0001$ vs. AvOX; ${ }^{\circledR} \mathrm{P}<0.05$ and ${ }^{@} @ @ @ \mathrm{P}<0.0001$ vs. Cis; ${ }^{\S \S} \mathrm{P}<0.01$ vs. AvOX+bCet; $\wedge \mathrm{P}<0.05$ vs. bCet+Cis. $\gamma-\mathrm{H} 2 \mathrm{~A} . \mathrm{X}, \gamma-\mathrm{H} 2 \mathrm{~A}$ histone family member X; AvOX, AvidinOX; bCet, biotinylated cetuximab; Cis, cisplatin.

in mice bearing subcutaneous tumor xenografts treated with systemic low doses of bCet (13). The current study demonstrated that this therapeutic approach is also effective in an orthotopic model (tongue xenograft) and that efficacy can be further improved by adding a low dose of cisplatin to the treatment protocol. Significant tumor reduction, together with a lack of body weight loss, lead us to foresee that this treatment might have a good therapeutic index. 


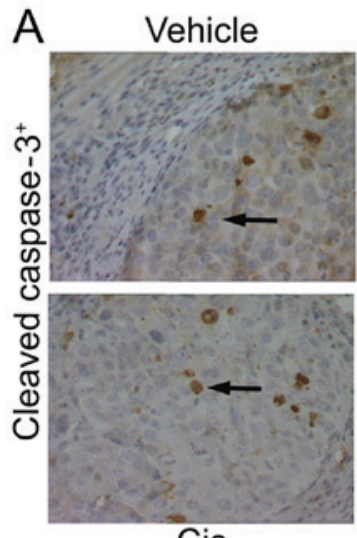

Cis
AvOX

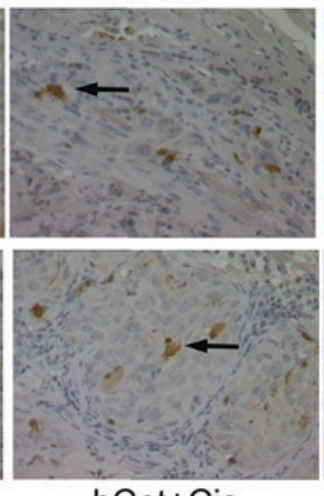

$\mathrm{bCet}+\mathrm{Cis}$
bCet
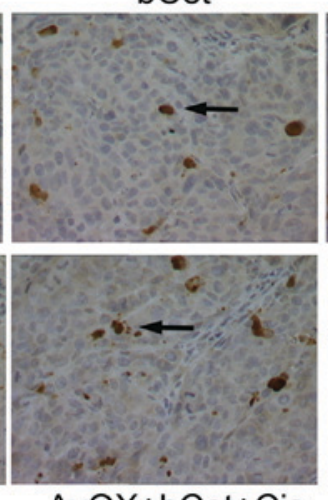

$\mathrm{AvOX}+\mathrm{bCet}+\mathrm{Cis}$
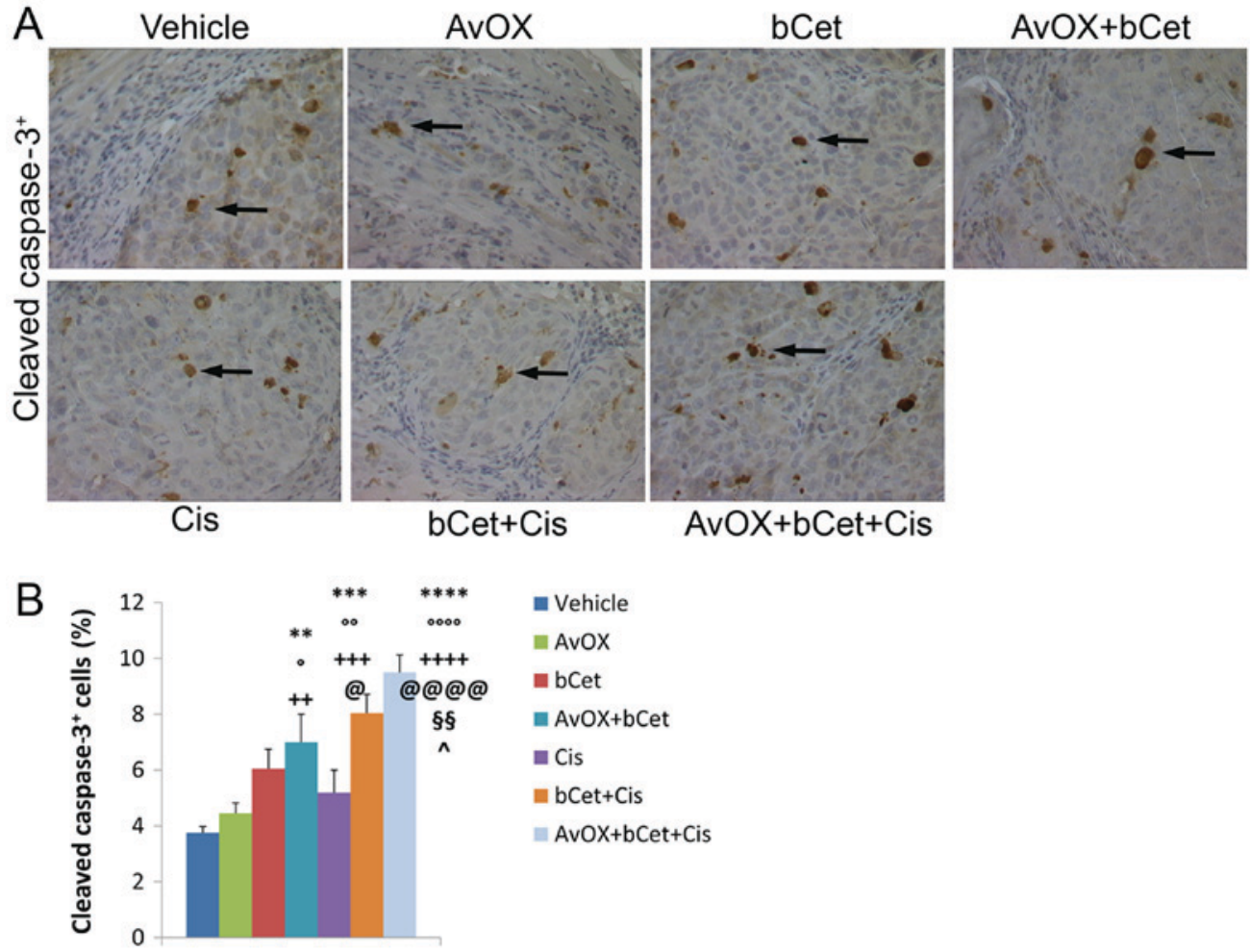

\author{
a Vehicle \\ m AvOX \\ $m$ bCet \\ m AvOX+bCet \\ a $\mathrm{Cis}$ \\ abet+Cis \\ AvOX+bCet+Cis
}

Figure 3. Low dose Cis increases the AvOX-dependent induction of cleaved caspase-3 positive tumor cells by bCet. (A) Representative images of cleaved caspase-3 staining (brown cells indicated by arrows). Magnification, $\mathrm{x} 40$. (B) Data are presented as the mean \pm standard error ( $\mathrm{n}=10$ mice per group) of positive cells x 100/total cells counted by two independent observers in five randomly selected fields. Results were compared using two-way analysis of variance followed by Bonferroni's multiple comparison test. ${ }^{* * *} \mathrm{P}<0.01,{ }^{* * * *} \mathrm{P}<0.001$ and ${ }^{* * * * *} \mathrm{P}<0.0001$ vs. vehicle-treated group; ${ }^{\circ} \mathrm{P}<0.05,{ }^{\circ} \mathrm{P}<0.01$ and ${ }^{0000} \mathrm{P}<0.0001$ vs. bCet; ${ }^{++} \mathrm{P}<0.01,{ }^{++} \mathrm{P}<0.001$ and ${ }^{+++} \mathrm{P}<0.0001$ vs. AvOX; ${ }^{\circledR} \mathrm{P}<0.05$ and ${ }^{\circledR @ @ @ @ ~} \mathrm{P}<0.0001$ vs. Cis; ${ }^{\$}{ }^{\$} \mathrm{P}<0.01$ vs. AvOX+bCet; $\wedge \mathrm{P}<0.05$ vs. bCet+Cis. AvOX, AvidinOX; bCet, biotinylated cetuximab; Cis, cisplatin.

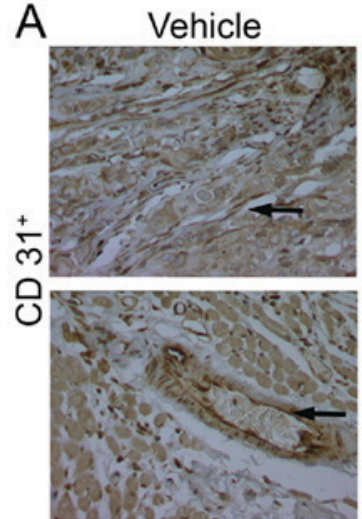

Cis
AvOX
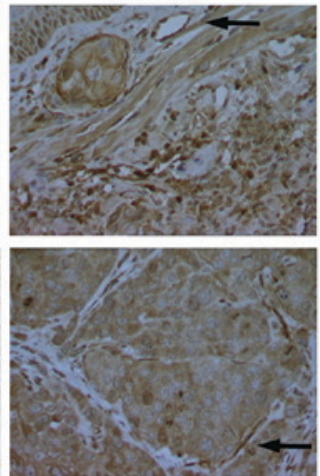

bCet+Cis
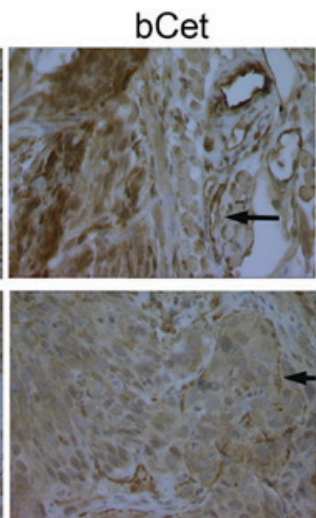

$\mathrm{AvOX}+\mathrm{bCet}+\mathrm{Cis}$
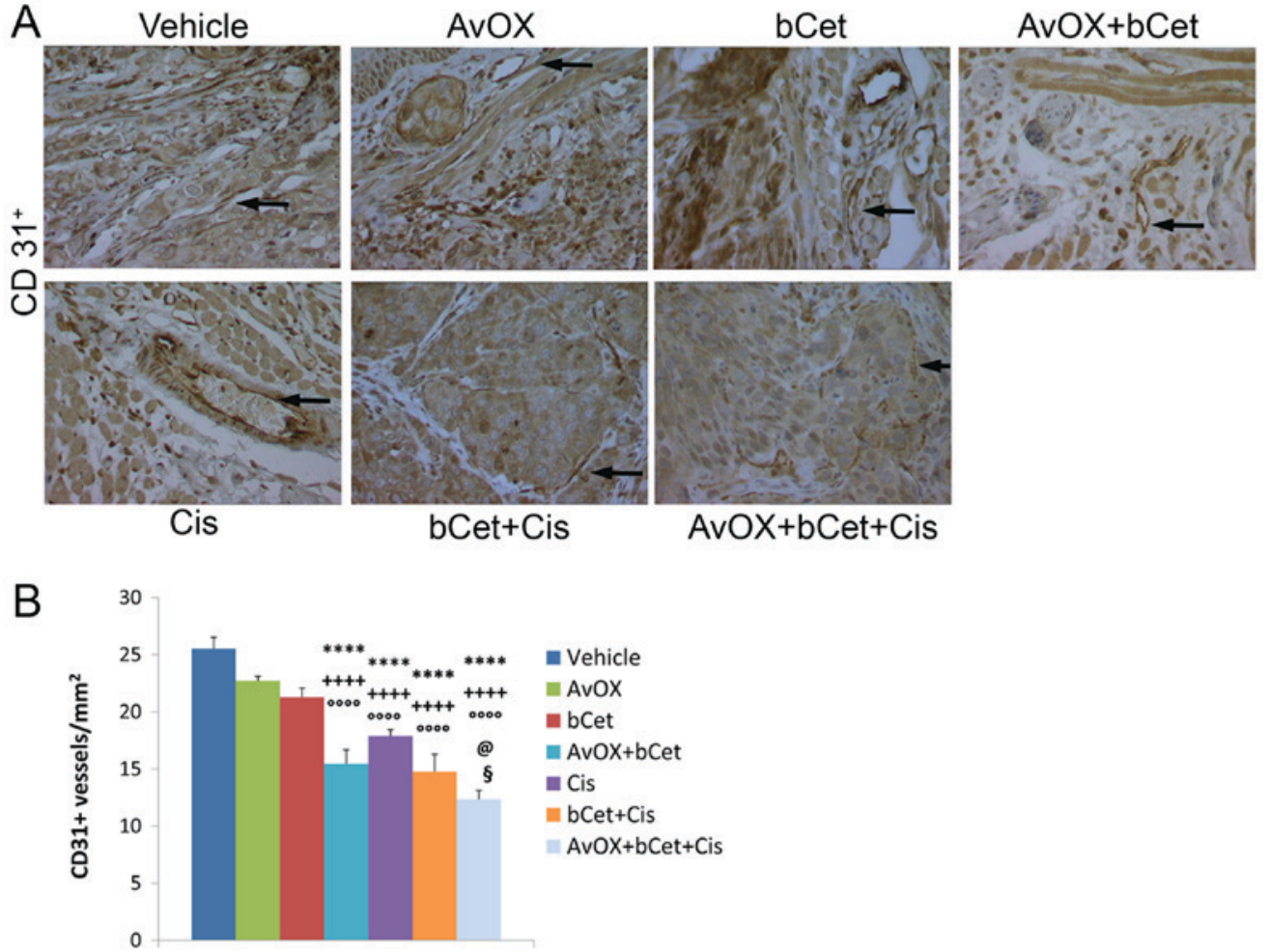

Figure 4. Low dose Cis improves the AvOX-dependent inhibition of CD31 positive cells by bCet. (A) Representative images of CD31 staining (brown cells indicated by arrows). Magnification, $\mathrm{x} 40$. (B) Data are presented as the mean \pm standard error ( $\mathrm{n}=10$ mice per group) of positive cells $\mathrm{x} 100 /$ total cells counted by two independent observers in five randomly selected fields. Results were compared using two-way analysis of variance followed by Bonferroni's multiple comparison test. ${ }^{* * * * *} \mathrm{P}<0.0001$ vs. vehicle-treated group; ${ }^{000} \mathrm{P}<0.0001$ vs. bCet; ${ }^{++++} \mathrm{P}<0.0001$ vs. AvOX; ${ }^{\circledR} \mathrm{P}<0.05$ vs. Cis; ${ }^{\circledR} \mathrm{P}<0.05$ vs. AvOX+bCet. AvOX, AvidinOX; bCet, biotinylated cetuximab; Cis, cisplatin; CD31, platelet and endothelial cell adhesion molecule 1. 


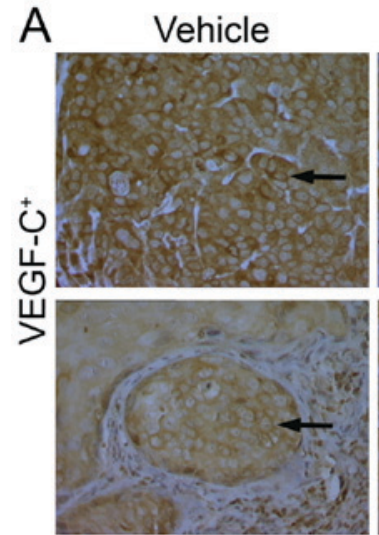

Cis
AvOX

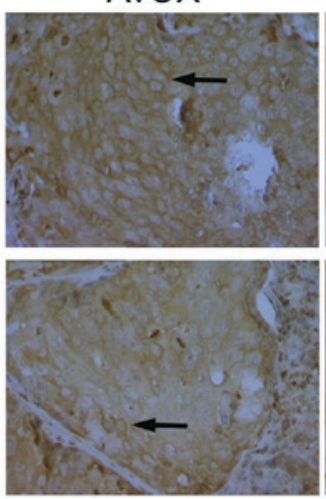

bCet+Cis
bCet

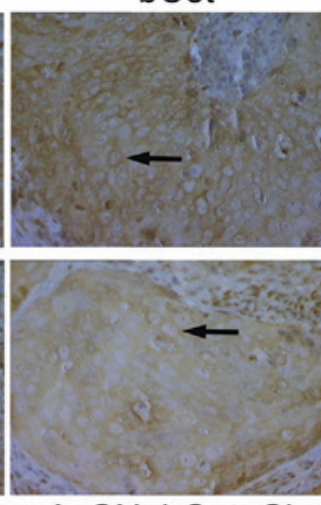

$\mathrm{AvOX}+\mathrm{bCet}+\mathrm{Cis}$

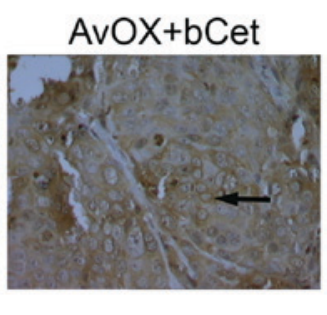

B

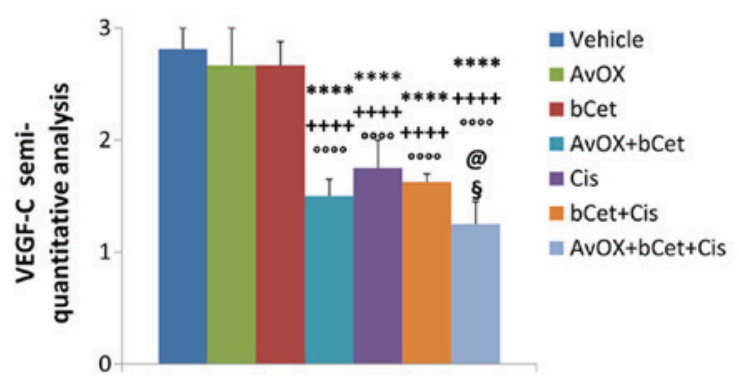

Figure 5. Low dose Cis improves the AvidinOX-dependent inhibition of VEGF-C expression by bCet. (A) Representative images of VEGF-C staining (brown cells indicated by arrows). Magnification, $x 40$. (B) Data are presented as the mean \pm standard error ( $\mathrm{n}=10 \mathrm{mice}$ per group) of a score estimated by two independent observers in five randomly selected fields. Negative staining, score $0 ; 1-20 \%$ positive cells, score $1+; 21-50 \%$ positive cells, score $2+;>50 \%$ positive cells, score $3+$. Results were compared using two-way analysis of variance followed by Bonferroni's multiple comparison test. ${ }^{* * * * *} \mathrm{P}<0.0001$ vs. vehicle-treated group; ${ }^{\circ 00} \mathrm{P}<0.0001$ vs. bCet; ${ }^{++++} \mathrm{P}<0.0001$ vs. AvOX; ${ }^{\circledR} \mathrm{P}<0.05$ vs. Cis; ${ }^{\circledR} \mathrm{P}<0.05$ vs. AvOX+bCet. AvOX, AvidinOX; bCet, biotinylated cetuximab; Cis, cisplatin; VEGF-C, vascular endothelial growth factor-C.

With regards to the tumor mass, the AvidinOX+bCet+cis treatment caused the highest tumor inhibition, which was significantly increased compared with all other treatment groups, including bCet+cis. This result, also validated by histological evaluation of DNA damage and apoptosis, indicated that AvidinOX significantly improved the effects of cetuximab and cisplatin. Overall, data highlight that induction of apoptosis of $\mathrm{FaDu}$ cells can be increased by the addition of cisplatin to AvidinOX-targeted bCet treatment. It is to note that a defect of the apoptotic signaling in other tumor cells could make them cisplatin resistant (21). For example, tumor cells lacking a functional p53 that it is known to promote cisplatin-dependent apoptosis by binding to cisplatin-modified DNA and by counteracting the anti-apoptotic function of $\mathrm{Bcl}-\mathrm{xL}$ (22), might resist cisplatin-induced apoptosis while being still responsive to AvidinOX-anchored bCet.

However, AvidinOX apparently did not have a significant effect on angiogenesis markers compared with the bCet+cis treatment. We speculate that while AvidinOX increases the bCet tumor toxicity, its effect, if any, on angiogenesis is not direct. In other words, we previously described that when EGFR is engaged by AvidinOX-anchored biotinylated anti-EGFR antibodies, the receptor physiology is compromised as measured by inhibition of receptor internalization and nuclear translocation and by increased lysosomal degradation, all leading to tumor cell death $(13,20)$. On the other hand, we believe that the AvidinOX-anchorage of biotinylated anti-EGFR antibodies has no direct effects on angiogenesis thus not significantly improving the activity of bCet+cis. Lymphangiogenesis has a central role in the formation of lymph node metastases in HNC patients and, besides common markers like CD31 and VEGF-C here addressed, there are several additional markers like podoplanin and Lyve-1 that are now being correlated with propensity to metastatization (23). Therefore, further studies will be necessary to understand if AvidinOX+bCet+cis might offer some advantage in controlling lymphangiogenesis, compared to standard cetuximab+cisplatin treatment protocols.

Finally, yet importantly, the present study demonstrated the feasibility of using AvidinOX-based approaches in combinatorial protocols, which are becoming increasingly popular to prevent or bypass tumor resistance (24). Additionally, we demonstrated the use of adding cisplatin to the AvidinOX-targeted bCet treatment combination. The next logical combination could be the addition of radioactive biotin. In fact, irradiation, in combination with chemotherapy or immunotherapy, is the most commonly used therapeutic option for HNC (25), and we previously demonstrated the therapeutic efficacy of ${ }^{90} \mathrm{Y}$-BiotinDOTA $\left({ }^{90} \mathrm{Y}-\mathrm{ST} 2210\right)$ in a model of tongue cancer (12). Considering these results, AvidinOX-driven protocols could be used to explore additional treatment combinations, including other biotinylated monoclonal antibodies against EGFR family members (such as anti-ErbB2) (20), antibodies against check point inhibitors with or without radioactive biotin, or other drugs/devices, as currently pursued in several clinical protocols (26-29). 


\section{Acknowledgements}

The authors would like to thank Professor Luigi Giusto Spagnoli (Histo-cyto Service, Rome, Italy) for supervising the immunohistochemistry procedures.

\section{Funding}

The present study was supported by Alfasigma S.p.A (Rome, Italy).

\section{Availability of data and materials}

The datasets used and/or analyzed during the present study are available from the corresponding author on reasonable request.

\section{Authors' contributions}

RDS conceived the study and wrote the manuscript. LV designed the study, analyzed the data and wrote the manuscript. AR established the tumor model and performed the treatments. VC conducted the immunohistochemistry analyses. All authors have read and approved the final manuscript.

\section{Ethics approval and consent to participate}

The present study was approved by the Ethics Committee of Alfasigma S.p.A. (Pomezia, Rome, Italy).

\section{Patient consent for publication}

Not applicable.

\section{Competing interests}

LV, AR and RDS are employees of Alfasigma S.p.A. which holds the patents of AvidinOX.

\section{References}

1. De Felice F, Polimeni A, Valentini V, Brugnoletti O, Cassoni A, Greco A, De Vincentiis M and Tombolini V: Radiotherapy controversies and prospective in head and neck cancer: A literature-based critical review. Neoplasia 20: 227-232, 2018.

2. Vermorken JB, Stöhlmacher-Williams J, Davidenko I, Licitra L, Winquist E, Villanueva C, Foa P, Rottey S, Skladowski K, Tahara M, et al: Cisplatin and fluorouracil with or without panitumumab in patients with recurrent or metastatic squamous-cel carcinoma of the head and neck (SPECTRUM): An open-label phase 3 randomised trial. Lancet Oncol 14: 697-710, 2013.

3. Vermorken JB, Licitra L, Stöhlmacher-Williams J, Dietz A, Lopez-Picazo JM, Hamid O, Hamid O, Hossain AM, Chang SC and Gauler TC: Phase II study of pemetrexed in combination with cisplatin and cetuximab in recurrent or metastatic squamous cell carcinoma of the head and neck. Eur J Cancer 49: 2877-2883, 2013.

4. Ang KK, Zhang Q, Rosenthal DI, Nguyen-Tan PF, Sherman EJ, Weber RS, Galvin JM, Bonner JA, Harris J, El-Naggar AK, et al: Randomized phase III trial of concurrent accelerated radiation plus cisplatin with or without cetuximab for stage III to IV head and neck carcinoma: RTOG 0522. J Clin Oncol 32: 2940-2950, 2014.

5. Martins RG, Parvathaneni U, Bauman JE, Sharma AK, Raez LE, Papagikos MA, Yunus F, Kurland BF, Eaton KD, Liao JJ, et al: Cisplatin and radiotherapy with or without erlotinib in locally advanced squamous cell carcinoma of the head and neck: A randomized phase II trial. J Clin Oncol 31: 1415-1421, 2013.
6. Numico G, Franco P, Cristofano A, Migliaccio F, Spinazzé S Silvestris N, Cante D, Sciacero P, La Porta MR, Girelli F and Ricardi U: Is the combination of Cetuximab with chemo-radiotherapy regimens worthwhile in the treatment of locally advanced head and neck cancer? A review of current evidence. Crit Rev Oncol Hematol 85: 112-120, 2013.

7. De Santis R, Albertoni C, Rosi A, Leoni B, Petronzelli F, D'Alessio V,Nucera E, Salvatori G, Paganelli G, Verdoliva A, et al: OXavidin for tissue targeting biotinylated therapeutics. J Biomed Biotechnol 2009: 921434, 2009.

8. De Santis R, Leoni B, Rosi A, Albertoni C, Forni G, Cojoca R, Iezzi M, Musiani P, Paganelli G, Chinol M and Carminati P: AvidinOX for highly efficient tissue-pretargeted radionuclide therapy. Cancer Biother Radiopharm 25: 143-148, 2010.

9. De Santis R, Anastasi AM, Pelliccia A, Rosi A, Albertoni C, Verdoliva A, Petronzelli F, D'Alessio V, Serani S and Nuzzolo CA: Chemical linkage to injected tissues is a distinctive property of oxidized avidin. PLoS One 6: e21075, 2011.

10. Nucera E, Nicoletti C, Chiapparino C, Pacello ML, D'Alessio V, Musarò A and De Santis R: AvidinOX\&\#x2122; for tissue targeted delivery of biotinylated cells. Int $\mathbf{J}$ Immunopathol Pharmacol 25: 239-246, 2012.

11. Verdoliva A, Bellofiore P, Rivieccio V, Catello S, Colombo M, Albertoni C, Rosi A, Leoni B, Anastasi AM and De Santis R: Biochemical and biological characterization of a new oxidized avidin with enhanced tissue binding properties. J Biol Chem 285: 9090-9099, 2010.

12. Albertoni C, Leoni B, Rosi A, D'Alessio V, Carollo V, Spagnoli LG, van Echteld C and De Santis R: Radionuclide therapy of unresectable tumors with AvidinOX and (90) Y-biotinDOTA: Tongue cancer paradigm. Cancer Biother Radiopharm 30: 291-298, 2015.

13. Vesci L, Milazzo FM, Anastasi AM, Petronzelli F, Chiapparino C, Carollo V, Roscilli G, Marra E, Luberto L, Aurisicchio L, et al: Intra-tumor AvidinOX allows efficacy of low dose systemic biotinylated Cetuximab in a model of head and neck cancer. Oncotarget 7: 914-928, 2016.

14. Urbano N, Papi S, Ginanneschi M, De Santis R, Pace S, Lindstedt R, Ferrari L, Choi S, Paganelli G and Chinol M: Evaluation of a new biotin-DOTA conjugate for pretargeted antibody-guided radioimmunotherapy (PAGRIT). Eur J Nucl Med Mol Imaging 34: 68-77, 2007.

15. Kilkenny C, Browne WJ, Cuthill JC, Emerson M and Altman DG: Improving bioscence research reporting: The ARRIVE guidelines for reporting animal research. Osteoarthritis Cartilage 20: 256-260, 2012.

16. Massi D, Puig S, Franchi A, Malvehy J, Vidal-Sicart S, González-Cao M, Baroni G, Ketabchi S, Palou J and Santucci M: Tumour lymphangiogenesis is a possible predictor of sentinel lymph node status in cutaneous melanoma: A case-control study. J Clin Pathol 59: 166-173, 2006.

17. Schneider CA, Rasband WS and Eliceiri KW: NIH image to imageJ: 25 years of image analysis. Nat Methods 9: 671-675, 2012.

18. Romanelli S, Perego P, Pratesi G, Carenini N, Tortoreto M and Zunino F: In vitro and in vivo interaction between cisplatin and topotecan in ovarian carcinoma systems. Cancer Chemother Pharmacol 41: 385-390, 1998.

19. De Santis R, Rosi A, Anastasi AM, Chiapparino C, Albertoni C, Leoni B, Pelliccia A, Santapaola D, Carollo V, Marra E, et al: Efficacy of aerosol therapy of lung cancer correlates with EGFR paralysis induced by AvidinOX-anchored biotinylated Cetuximab. Oncotarget 5: 9239-9255, 2014.

20. Milazzo FM, Anastasi AM, Chiapparino C, Rosi A, Leoni B, Vesci L, Petronzelli F and De Santis R: AvidinOX-anchored biotinylated trastuzumab and pertuzumab induce down-modulation of ErbB2 and tumor cell death at concentrations order of magnitude lower than not-anchored antibodies. Oncotarget 8: 22590-22605, 2017.

21. Dasari S and Tchounwou PB: Cisplatin in cancer therapy: Molecular mechanisms of action. Eur J Pharmacol 740: 364-378, 2014.

22. Basu A and Krishnamurthy S: Cellular responses to cisplatin-induced DNA damage. J Nucleic Acids 2010: pii: 201367, 2010.

23. Arimoto S, Hasegawa T, Takeda D, Saito I, Amano R, Akashi $\mathrm{M}$ and Komori $\mathrm{T}$ : Lymphangiogenesis and lymph node metastasis in oral squamous cell carcinoma. Anticancer Res 38: 6157-6162, 2018.

24. Lonser RR, Sarntinoranont M, Morrison PF and Oldfield EH: Convection-enhanced delivery to the central nervous system. J Neurosurg 122: 697-706, 2015. 
25. Beitler JJ, Zhang Q, Fu KK, Trotti A, Spencer SA, Jones CU, Garden AS, Shenouda G, Harris J and Ang KK: Final results of local-regional control and late toxicity of RTOG 9003: A randomized trial of altered fractionation radiation for locally advanced head and neck cancer. Int J Radiat Oncol Biol Phys 89: 13-20, 2014.

26. Kfoury M, Disdero V, Vicier C, Le Saux O, Gougis P, Sajous C and Vignot S: Immune checkpoints inhibitors: Recent dat from ASCO's meeting 2017 and perspectives. Bull Cancer 105: 686-695, 2018 (In French).
27. Yoneda K, Imanishi N, Ichiki Y and Tanaka F: Immune checkpoint inhibitors (ICIs) in non-small cell lung cancer (NSCLC). J UOEH 40: 173-189, 2018.

28. Durante M and Formenti SC: Radiation-induced chromosomal aberrations and immunotherapy: Micronuclei, cytosolic DNA, and interferon-production pathway. Front Oncol 8: 192, 2018.

29. Ni K, Lan G, Chan C, Quigley B,Lu K, Aung T, Guo B, La Riviere P, Weichselbaum RR and Lin W: Nanoscale metal-organic frameworks enhance radiotherapy to potentiate checkpoint blockade immunotherapy. Nat Commun 9: 2351, 2018. 